\title{
Promising plasmid DNA vector based on APTES- modified silica nanoparticles
}

This article was published in the following Dove Press journal:

International Journal of Nanomedicine

22 February 2012

Number of times this article has been viewed

\author{
Tuck-yun Cheangl* \\ Bing Tang ${ }^{*}$ \\ An-wu $X u^{2}$ \\ Guang-qi Chang' \\ Zuo-jun $\mathrm{Hu}^{\prime}$ \\ Wei-ling $\mathrm{He}^{1}$ \\ Zhou-hao Xing ${ }^{2}$ \\ Jian-bo $X u^{\prime}$ \\ Mian Wang' \\ Shen-ming Wang' \\ 'Department of Vascular Surgery, The \\ First Affiliated Hospital of Sun \\ Yat-sen University, Guangzhou, China; \\ ${ }^{2}$ Division of Nanomaterials and \\ Chemistry, Hefei National Laboratory \\ for Physical Sciences at Microscale, \\ University of Science and Technology \\ of China, Hefei, China
}

*Both authors contributed equally to this work

Correspondence: Shen-ming Wang Department of Vascular Surgery, The First Affiliated Hospital of Sun Yat-sen University, Guangzhou 510080, China

Tel +86 I330222 4I68

Fax +86208775 5766

Email shenmingwang@vip.sohu.com

An-wu Xu

Division of Nanomaterials and Chemistry, Hefei National Laboratory for Physical

Sciences at Microscale, University

of Science and Technology of China,

Hefei 230026, China

Tel +86 I38 56000072

Fax +86 55I 3600724

Email anwuxu@ustc.edu.cn
Abstract: Nanoparticles have an enormous potential for development in biomedical applications, such as gene or drug delivery. We developed and characterized aminopropyltriethoxysilanefunctionalized silicon dioxide nanoparticles (APTES-SiNPs) for gene therapy. Lipofectamine ${ }^{\circledR}$ 2000, a commonly used agent, served as a contrast. We showed that APTES-SiNPs had a gene transfection efficiency almost equal to that of Lipofectamine 2000, but with lower cytotoxicity. Thus, these novel APTES-SiNPs can achieve highly efficient transfection of plasmid DNA, and to some extent reduce cytotoxicity, which might overcome the critical drawbacks in vivo of conventional carriers, such as viral vectors, organic polymers, and liposomes, and seem to be a promising nonviral gene therapy vector.

Keywords: aminopropyltriethoxysilane, silicon dioxide nanoparticles, Lipofectamine ${ }^{\circledR} 2000$, gene therapy vector, nanomedicine

\section{Introduction}

Nanomedicine is an emerging new field created by fusion of nanotechnology and medicine in a straightforward manner by adding, correcting, or replacing genes. A key problem in gene therapy is the efficient delivery of genetic material to target cells in a patient without significant toxicity and side effects. A number of novel delivery strategies have been proposed to enhance the efficiency of plasmid DNA (pDNA) transfection. Nevertheless, the reliability of the carrier is still a critical concern for any gene therapy. An ideal gene delivery system should be biodegradable, nontoxic, nonimmunogenic, stable, and target-specific, should assist to improve gene expression, and be able to be used to treat genetic diseases which require systemic administration of therapy.

Nanoscale gene carriers traditionally include viral vectors, organic polymers, and liposomes. ${ }^{1,2}$ Viral vectors have been used widely for effective DNA delivery, but their potential immune response, difficult recombination, and high cost have hampered their applications. ${ }^{3}$ Nonviral polymer carriers have more potential for gene and drug delivery because of such advantages as easy preparation and reduced risk of immune response. Cationic polymers and liposomes have recently shown promise, ${ }^{4,5}$ and solid lipid nanoparticles have also been shown to be a useful vehicle for gene therapy. ${ }^{6}$ However, any benefits due to their cationic nature are offset by their instability in serum and high cytotoxicity profile. A number of approaches have been attempted to overcome the cytotoxicity limitation and to make nonviral cationic systems safer. ${ }^{7}$ An ideal method with both high transfection efficiency and relative safety in vitro and in vivo has not been found, so more attention needs to be devoted to finding new materials. 
Fortunately, inorganic nanoparticles such as those made from hydroxyapatite and silicon, offer promise as gene and drug transfer carriers because of their biocompatibility, lack of toxicity, and stable physical and chemical properties. ${ }^{8}$ Silicon nanoparticles have been used recently as gene carriers in the transfection of pDNA. ${ }^{9}$

Furthermore, enormous effort has been devoted to surface modification of various polymer drug vectors in order to improve their biocompatibility, resist protein adsorption, and increase their circulation time and internalization efficiency. ${ }^{10}$ Common functionalization procedures for preparing surfaces for protein binding utilize silane compounds with terminal functional groups that interact electrostatically or covalently with protein surface groups to increase protein adsorption. One common chemical used for surface functionalization is aminopropyltriethoxysilane (APTES), which has the chemical formula $\mathrm{NH}_{2}\left(\mathrm{CH}_{2}\right)_{3}-\mathrm{Si}\left(\mathrm{OC}_{2} \mathrm{H}_{5}\right)_{3} \cdot{ }^{11-14}$ The silane end of the APTES molecule binds covalently to surface silicon atoms, and the amino end of the molecule increases protein adsorption on the surface by electrostatic interactions. The structural transition of a single dsDNA molecule immobilized on an APTES-treated substrate has been demonstrated. DNA binding to the APTES linker is much stronger than that on an alkylthiol/substrate. ${ }^{15}$ Also, APTES can dissolve in both polar and nonpolar solvents, and also has high solubility in cell membranes. ${ }^{16,17}$

Here we report a pDNA carrier based on APTESmodified silica nanoparticles (APTES-SiNPs), the surface of which was functionalized with TX-100 in order to enhance its monodispersity. It was produced by a guided self-assembly approach to the manufacture of DNA nanostructures on a silicon substrate. Because of the unique profiles of APTES and the silica nanoparticles, the novel APTES-SiNP vector has a large surface area to volume ratio, tends to agglomerate, and absorbs more pDNA.

In order to evaluate the transfection efficiency and safety of APTES-SiNPs, we investigated the ability of these novel nanoparticles to condense the plasmid encoding for enhanced green fluorescent protein (pEGFP) and transfer it into human vascular smooth muscle cells (HVSMCs). Using this approach, we compared the stability, plasmid immobilization, transfection efficiency, and cytotoxicity of this formulation with widely used conventional Lipofectamine ${ }^{\circledR} 2000$ in order to evaluate its potential as a gene transfection vector.

\section{Materials and methods Materials}

All chemicals, ie, APTES (Alfa Aesar, Ward Hill, MA), methyltrimethoxysilane (Alfa Aesar), and Triton X-100
(Sigma-Aldrich, St Louis, MO) were used without further purification. All the glassware (glass bottle and small pieces of glass substrate) was cleaned and sonicated in ethanol for 5 minutes, rinsed with double distilled water, soaked in a $\mathrm{H}_{2} \mathrm{O} / \mathrm{HNO}_{3}(65 \%) / \mathrm{H}_{2} \mathrm{O}_{2}(1: 1: 1, \mathrm{v} / \mathrm{v} / \mathrm{v})$ solution, rinsed again with doubly distilled water, and finally dried in air.

\section{Synthesis of ATPES-SiNPs}

APTES $0.1 \mathrm{~mL}$ and TX-100 $0.3 \mathrm{~mL}$ were dissolved in $20 \mathrm{~mL}$ of double distilled water and stirred for 10 minutes. Methyltrimethoxysilane $2 \mathrm{~mL}$ was added, followed by stirring for 10 minutes, with subsequent addition of $28 \% \mathrm{NH}_{3} \mathrm{H}_{2} \mathrm{O}$ to reach a $\mathrm{pH}$ of 11 . The solution was stirred for 5 hours, then left overnight at room temperature. Finally, the product was collected by centrifugation, rinsed with double distilled water and ethanol, and allowed to dry at room temperature.

\section{Agarose gel electrophoresis}

Complex formation between the nanoparticles and pDNA was analyzed by $1 \%$ agarose gel electrophoresis. The pDNA-APTES complex was prepared according to the following process. Briefly, $1 \mu \mathrm{L}$ of APTES-SiNP in solution ( $5 \mathrm{mg} / 500 \mu \mathrm{L}$ in water) was added to $1 \mu \mathrm{L}$ of pDNA aqueous solution $(0.1 \mu \mathrm{g} / \mu \mathrm{L})$ and $8 \mu \mathrm{L}$ water $(\mathrm{pH} 7.4)$ in a microcentrifuge tube. The resulting pDNA/APTES-SiNP complexes were left at room temperature for 30 minutes to facilitate complexation. The samples were centrifuged at $5000 \mathrm{rpm}$ for 5 minutes, after which the suspension was obtained and analyzed by loading onto $1 \%$ agarose gel with ethidium bromide $(0.1 \mu \mathrm{g} / \mathrm{mL})$ and running with Tris-acetate buffer at $100 \mathrm{~V}$ for 30 minutes. DNA retardation was observed by irradiation with ultraviolet light.

\section{Transfection of cultured cells}

HVSMCs were cultured in $75 \mathrm{~cm}^{2}$ flasks in Dulbecco's modified Eagle's medium (Gibco BRL, Carlsbad, CA) supplemented with $10 \%$ fetal bovine serum, $50 \mathrm{Ag} / \mathrm{mL}$ penicillin, $50 \mathrm{Ag} / \mathrm{mL}$ streptomycin, and $100 \mathrm{Ag} / \mathrm{mL}$ neomycin at $37^{\circ} \mathrm{C}$ in a humidified $5 \% \mathrm{CO}_{2}$-containing atmosphere. For the transfection experiments, the cells were trypsinized and seeded into a 6 -well plate at a density of $2.5 \times 10^{5}$ cells/well overnight before the transfection procedure was performed. The cells were washed with phosphate-buffered solution twice prior to the addition of Optimen ${ }^{\circledR} 2 \mathrm{~mL}$. The transfection procedure consisted of $12 \mu \mathrm{L}$ pEGFP $(185 \mu \mathrm{g} / \mathrm{mL})$ with $12 \mu \mathrm{L}$ APTES-SiNP solution (APTES-SiNPs $5 \mathrm{mg} /$ TrisEDTA $500 \mu \mathrm{L}$ ), and $18 \mu \mathrm{L}$ water ( $\mathrm{pH} 7.4$ ) in one microcentrifuge tube. The contents were then mixed together gently 
and incubated at room temperature for 30 minutes. The cells were then incubated at $37^{\circ} \mathrm{C}$ in $5 \% \mathrm{CO}_{2}$. After 5 hours, the complexes were aspirated and replaced with culture medium. After 48 hours, the cells were assayed for green fluorescent protein expression, both qualitatively by fluorescence microscopy and quantitatively by fluorescence-activated cell sorting. The cells were washed twice with phosphate-buffered solution and collected by trypsinization, centrifuged at $2000 \mathrm{~g}$ for 2 minutes, and washed twice with phosphate-buffered solution. The cells were then resuspended in phosphatebuffered solution and analyzed by flow cytometry (Beckman Coulter, Brea, CA).

\section{Statistical analysis}

All experimental measurements were collected in triplicate. The values are expressed as the mean \pm standard deviation. The statistical significance of differences in cell viability was examined using one-way analysis of variance followed by Fisher's least significant difference test. The significance level was set at $P<0.05$.

\section{Results and discussion Nanoparticle size and zeta potential measurement}

The nanoparticles were characterized by scanning electron microscopy and elemental analysis (x-ray photoelectron spectrometry, Figure 1). The mean size of the APTES-SiNPs was found to be $174.5 \mathrm{~nm}$ by dynamic light scattering.

Several approaches have been proposed to increase the surface area of the solid-phase support to enhance the capacity for DNA. Examples include the use of smallersized particles. Decreasing the particle size has proved to be an effective method of increasing the surface area for
DNA absorption. ${ }^{18}$ However, too small a particle size can cause extremely high back pressure during the extraction procedure. The monotonic decrease of the size of small particles to increase the surface area of the solid phase has consequently been limited in practical application. Nanomaterials with unique properties such as a large surface area, pore structure, embedded effect, and size effect have been used effectively in bioanalysis and drug delivery. ${ }^{19,20}$

After amino functionalization, zeta potential measurements carried out using a Beckman Delsa Nano $\mathrm{C}$ at an APTES-SiNP concentration of $1 \mathrm{~g} / \mathrm{L}$ at $20^{\circ} \mathrm{C}$ demonstrated that the APTES-SiNP particles had a positive surface potential of $+41.8 \mathrm{mV}$. We assessed pDNA condensation and integrity using gel electrophoresis (Figure 2). The positive potential might have resulted from protonation of amino groups on the surface of APTES-SiNPs. Therefore, the positively charged silica nanoparticles could be obtained directly without further modification and could combine with the negatively charged pDNA as a carrier for DNA delivery. The positively charged silica APTES-SiNPs could combine with negatively charged pDNA by electrostatic interactions to form APTES-SiNP-pDNA complexes.

A suitable ratio of silicon to pDNA was about 30:1, indicating that the positive charge density of APTES-SiNPs is not very high, considering their large diameter. Generally speaking, a lower positive charge density would reduce cytotoxicity.

\section{Gel electrophoresis analysis}

Binding of APTES-SiNPs to polyanionic pDNA was studied using the electrophoretic mobility of pDNA in agarose gel. The complexes were formed in deionized water by mixing a fixed amount of pDNA with increasing amounts of APTESSiNPs in such a way as to obtain APTES-SiNPs:pDNA

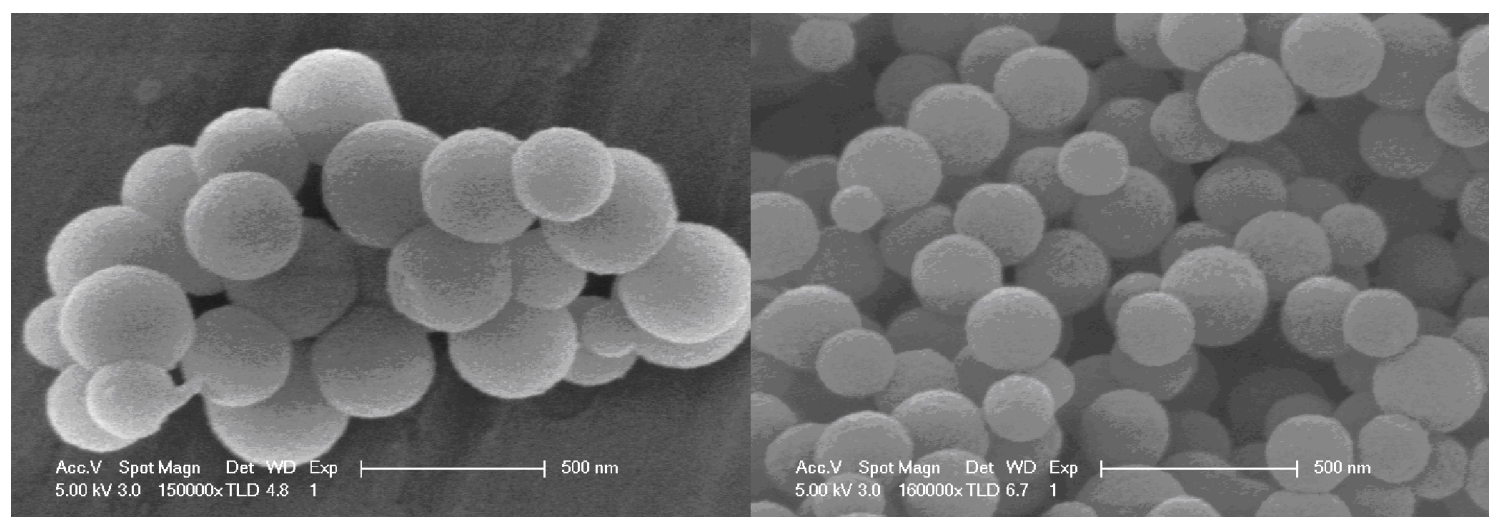

Figure I Scanning electron microscopic images of amino-modified silicon nanoparticles. Note: Bars, $500 \mathrm{~nm}$. 


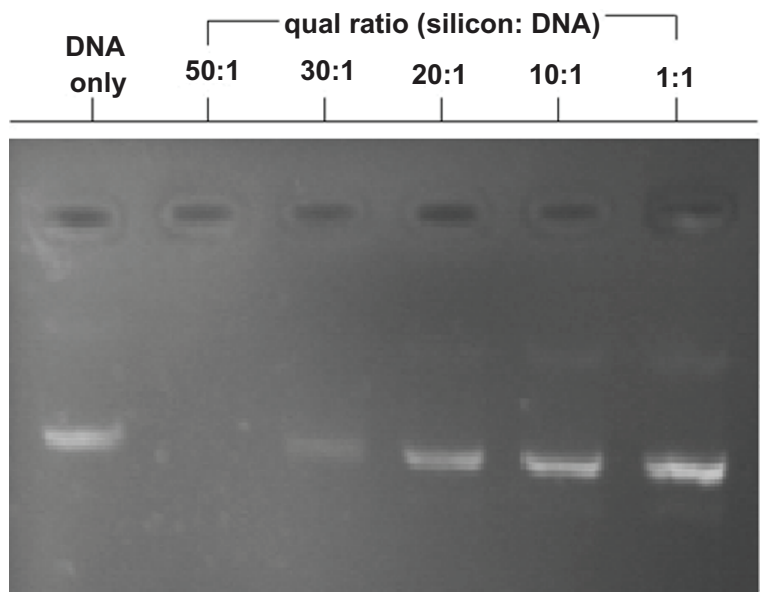

Figure 2 Agarose gel electrophoresis assay demonstrating APTES-SiNP-DNA complexation. A constant amount of DNA was complexed with nanoparticles at different ratios of 50:1, 30:I, 20:1, 10:1, and I:I (10 mM, pH 7.4). No 50:1 or 30:I APTES-SiNP-DNA band is observed because of fluorescence quenching by nanoparticle complexation.

Abbreviations: APTES, aminopropyltriethoxysilane; SiNP, silicon dioxide nanoparticle.

weight ratios ranging from $50: 1$ to $1: 1$, corresponding to the w/w ratio indicated in Figure 2. The efficiency of pDNA complexation with APTES-SiNPs after 30 minutes of incubation was evaluated by the amount of APTES-SiNPs required to retard migration of pDNA toward the cathode during agarose gel electrophoresis. Efficient complexation of pEGFP by APTES-SiNPs led to pDNA immobilization. As can be seen in Figure 2, at the higher two ratios of APTES-SiNPs:pDNA assayed, stable complexes were formed. The absence of DNA in lines 2 to 3 confirms that DNA was completely immobilized inside the complexes.

In summary, APTES-SiNPs have size and zeta potential values similar to those of other carriers and the same capacity to complex pDNA. Two bands (Figure 2) were characterized for their capacity to condense pDNA and to transfect HVSMCs.

\section{Cytotoxicity}

Gene vectors should not induce cytotoxic effects in gene therapy, ${ }^{21}$ so the low cytotoxicity of APTES-SiNPs:pDNA is very important. Nonviral delivery systems have certain drawbacks, such as cytotoxic reactions, especially when cationic lipids are involved. ${ }^{22}$ Cationic formulations have been reported to affect cell proliferation, differentiation, and proapoptotic genes in human epithelial cells. The polycationic nature of synthetic nonviral gene transfer systems induces cytotoxicity by necrosis and apoptosis.

Therefore, evaluation of the cytotoxicity of cationic gene delivery systems is essential. In the present study, the toxicity of APTES-SiNPs was compared with that of Lipofectamine 2000 in HVSMCs by flow cytometry in vitro, as shown in Figure 3. We observed that Lipofectamine 2000 was much more toxic than APTES-SiNP to cells.

Previous studies have shown that mesoporous silica nanoparticles are nontoxic and biocompatible,,$^{23,24}$ sufficiently excreted via the renal route, ${ }^{25}$ and promising candidates for drug delivery applications. ${ }^{25,26}$ Our study results are in accordance with those of a previous study showing that APTES-SiNPs have almost no adverse effects on human cells. However, there is an increasing body of evidence suggesting that the surface properties of nanoparticles can have considerable toxicity. ${ }^{27}$ The toxicity of cationic polymers has been reported to be a function of the interactions of the polymers with cell membranes and/or the efficiency of cellular uptake. ${ }^{28,29}$ As show in Figure 3, APTES-SiNPs actually do have some adverse effects on human cells, mainly ascribable to APTES. However, quaternized APTES derivatives show less cytotoxicity than regular APTES because they maintain a cationic charge inside the polymeric backbone shielded by surface hydroxyl groups. This could explain why the cytotoxicity of APTES is low after it is fixed onto silicon nanoparticles.

The higher cell viability observed for APTES-SiNPs is probably due to the better cell compatibility of the silicon particles. As a consequence, APTES-SiNPs maintain the same low level of cytotoxicity even at high particle concentrations and a long cell contact time.

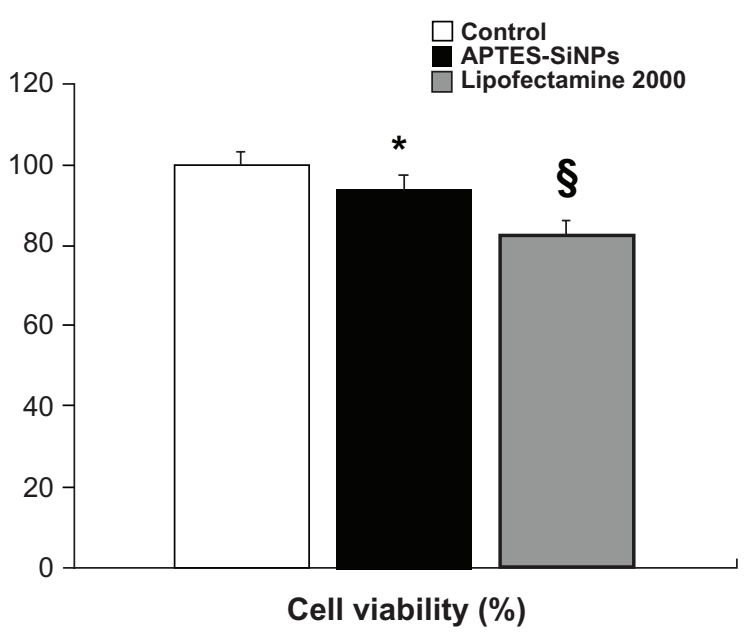

Figure 3 Cell viability assay. Cytotoxicity of Lipofectamine ${ }^{\circledR} 2000$ and APTES-SiNPs on human vascular smooth muscle cells. After 48 hours of incubation, cell viability was measured by flow cytometry. Silicon nanoparticles had negligible toxicity to human vascular smooth muscle cells compared with Lipofectamine 2000.

Notes: $* P<0.05$ for APTES-SiNPs versus control; $\$ P<0.05$ for Lipofectamine 2000 versus APTES-SiNPs.

Abbreviations: APTES, aminopropyltriethoxysilane; SiNPs, silicon dioxide nanoparticles. 


\section{Transfection}

In the present study, we found that the nature of the chemical groups on the surface of APTES-SiNPs is a critical factor affecting transfection efficiency. We modified the surface of the silicon nanoparticles and evaluated the ability of the mica to deliver the pEGFP gene into HVSMCs. Our results show that the APTES-SiNPs were able to deliver pEGFP into cells (Figures 4 and 5). They also suggest that the positive charge introduced by an amino group might allow the APTESSiNPs to bind to anionic pDNA and the cell membrane via electrostatic interactions, which could be the initial step for gene transfection.

We have developed an optimal method to protect DNA from cleavage by using bioconjugated amino-modified silicon nanoparticles. Our results clearly show that DNA could be easily enriched onto the positively charged surface of the nanoparticles for further manipulation. The DNA strands are protected from enzymatic cleavage and have the same properties as free DNA strands when released from the nanoparticles. The plasmids released are biologically active. This bionanotechnology is simple and efficient for protecting DNA strands. It will be highly useful in DNA separation, purification, manipulation, and detection, and possibly in genetic engineering and gene therapy.

The DNA delivery pathway involves the following steps. First, nanoparticles are adsorbed onto the cell membrane. The nanoparticles are then taken up by cells via endocytosis. ${ }^{30,31}$ Certain intracellular processes can avoid transport of DNA across the cell membrane into the nucleus. Endosomal degradation of DNA can occur during endocytosis inside an endosome if DNA does not escape from the endosome before fusion with lysosomes (in which $\mathrm{pH}$ is $<5$ ). ${ }^{32}$
In a previous study it was reported that hydrophilic APTES nanoparticles are actively taken up by tumor cells in vitro, as seen by fluorescence staining of the cytoplasm. ${ }^{33}$ This cytoplasmic staining has been observed for a few types of tumor cells that we have investigated, an example of which is HVSMCs. Although the mechanism for this type of cellular uptake is not yet fully understood, the net negative charge on the nanoparticles is thought to play a crucial role. A similar observation was made in a recent study that demonstrated high specific uptake of anionic magnetic nanoparticles by cells in vitro. ${ }^{34}$ In gene delivery, the genetic material should migrate to the nucleus as soon as it is released inside the cytoplasm of a cell. ${ }^{35}$ Again, optical imaging can play a significant role in studying this nuclear migration of DNA. In the present study, we irreversibly tagged DNA with fluorescent APTES-SiNPs and unlabeled silicon nanoparticle complexes, as described in the experimental program. The post-release nuclear trafficking of DNA is demonstrated in the confocal image of HVSMCs. After comparison of this image with the image of HVSMCs stained with amino-encapsulated nanoparticles, it can be seen that there is considerable staining inside the nucleus in addition to cytoplasmic staining (Figure 4). However, these amino-modified nanoparticles are not able to penetrate the cell nucleus. Thus, we believe that this nuclear staining is a result of migration of the labeled DNA released inside the nucleus. A recent study report on the mobility of DNA molecules inside cells indicates that free DNA molecules can move in the cytoplasm, and that a small portion of them can reach the intranuclear space. ${ }^{36}$

This nuclear accumulation of foreign DNA can be increased by tagging with nucleus-targeting peptides. ${ }^{37}$ Finally, to confirm that the DNA delivered is functional,

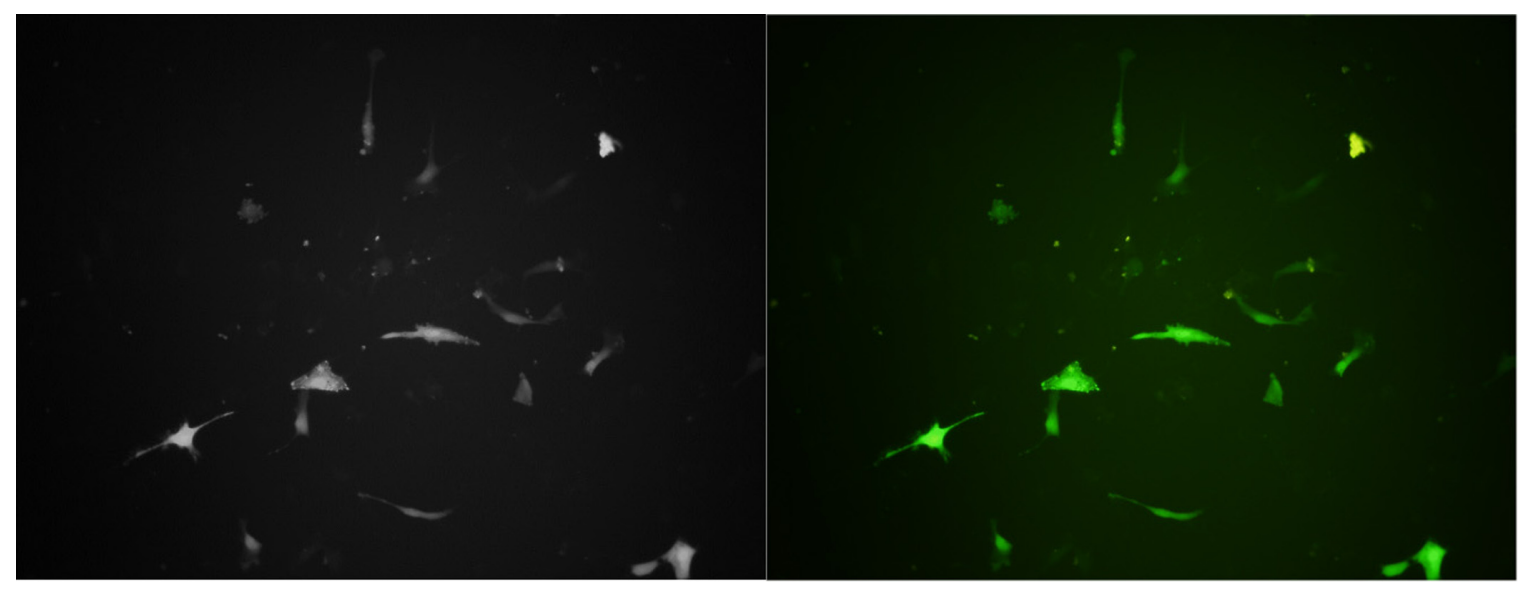

Figure 4 Human vascular smooth muscle cells transfected with pEGFP delivered with APTES-SiNPs. A combined transmission and fluorescence image is shown. Fluorescence spectra of pEGFP taken in human vascular smooth muscle cells (magnification 400x).

Abbreviations: APTES, aminopropyltriethoxysilane; SiNPs, silicon dioxide nanoparticles; pEGFP, plasmid encoding for enhanced green fluorescent protein. 


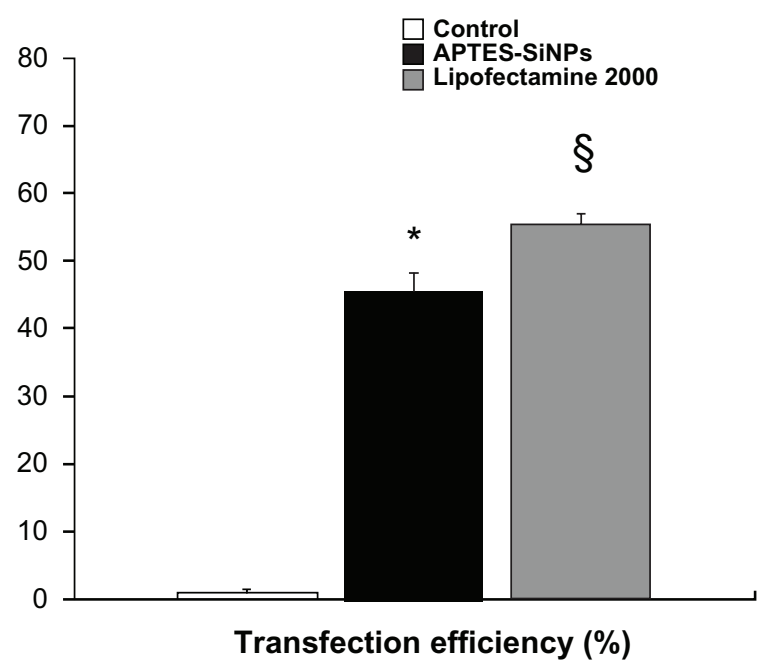

Figure 5 Cell transfection efficiency. The percentage of pEGFP expression was determined by flow cytometry after APTES-SiNP transfection in human vascular smooth muscle cells.

Notes: $* P<0.05$ for APTES-SiNPs versus control; ${ }^{\circledR P}<0.05$ for Lipofectamine 2000 versus APTES-SiNPs.

Abbreviations: APTES, aminopropyltriethoxysilane; SiNPs, silicon dioxide nanoparticles; pEGFP, plasmid encoding for enhanced green fluorescent protein.

pEGFP expression was checked by transfection of cultured cells. We observed that pEGFP was transfected successfully using APTES-SiNPs as the delivery vector. The observed green cellular fluorescence was from the expressed pEGFP, which was confirmed by localized spectroscopy (Figure 4). Our investigation shows that the nanomedicine approach using APTES-SiNPs is a promising direction for nonviral gene delivery.

\section{Conclusion}

In recent years, the transfection effect of nonviral carriers has been emphasized whilst overlooking the critical issue of cytotoxicity. Consequently, even though we have found many highly promising efficient carriers in vitro, their potential immune response, difficult recombination, and high cost has hampered their application in vivo. ${ }^{3}$ Undoubtedly, the basic requirement of a new carrier is transfection efficiency, but its safety is likely to play a pivotal role in its clinical application. We need to devote more attention to modification of the structural aspects of these carriers to minimize their toxicity and also find new materials, such as silicon nanoparticles, because transfection efficiency can be easily improved by increasing the weight ratio, whereas toxicity cannot be tackled so easily. Most new carriers found in recent years have been discarded upon practical application, for similar reasons.

In the present study, positively charged APTES-SiNPs with an average diameter of $174.5 \mathrm{~nm}$ were synthesized as pDNA carriers using a water-in-oil microemulsion method.
The positively charged APTES-SiNPs were able to combine with the negatively charged pDNA by electrostatic interactions to form a bioconjugate favorable for cellular uptake. The APTES-SiNPs were able to protect the pDNA in the complex from nuclease degradation. In vitro investigation suggested that the APTES-SiNP carriers could efficiently transfect pEGFP into HVSMCs, although the gene transfection efficiency was a little lower than that achieved by the more widely used Lipofectamine 2000 (Figure 5). It is worthwhile to emphasize that the toxicity of the APTES-SiNP carriers was lower than that of Lipofectamine 2000, and that they showed good biocompatibility and almost no cytotoxicity to HVSMCs. Further, the surface of APTES-SiNPs can also be chemically modified with various functional groups, such as cancer-specific antibodies or ligands, for targeting purposes. ${ }^{38-42}$ Considering all of the data, APTES-SiNPs may be superior to Lipofectamine 2000 as carriers of pDNA in HVSMCs, and may be a promising nonviral gene therapy vector.

\section{Disclosure}

The authors report no conflicts of interest in this work.

\section{References}

1. Bertling WM, Gareis M, Paspaleeva V, et al. Use of liposomes, viral capsids, and nanoparticles as DNA carriers. Biotechnol Appl Biochem. 1991;13(3):390-405.

2. Luo D, Saltzman WM. Synthetic DNA delivery systems. Nat Biotechnol. 2000;18(1):33-37.

3. Anderson WF. Human gene therapy. Nature. 1998;392(Suppl 6679): 25-30.

4. Li W, Szoka FC Jr. Lipid-based nanoparticles for nucleic acid delivery. Pharm Res. 2007;24(3):438-449.

5. Li SD, Huang L. Non-viral is superior to viral gene delivery. J Control Release. 2007;123(3):181-183.

6. del Pozo-Rodriguez A, Pujals S, Delgado D, et al. A proline-rich peptide improves cell transfection of solid lipid nanoparticle-based non-viral vectors. J Control Release. 2009;133(1):52-59.

7. Pack DW, Hoffman AS, Pun S, Stayton PS. Design and development of polymers for gene delivery. Nat Rev Drug Discov. 2005; 4(7):581-593.

8. Allen TM, Cullis PR. Drug delivery systems: entering the mainstream. Science. 2004;303(5665):1818-1822.

9. Roy I, Ohulchanskyy TY, Bharali DJ, et al. Optical tracking of organically modified silica nanoparticles as DNA carriers: a nonviral, nanomedicine approach for gene delivery. Proc Natl Acad Sci U S A. 2005;102(2):279-284

10. Storm G, ten Kate MT, Working PK, Bakker-Woudenberg IA. Doxorubicin entrapped in sterically stabilized liposomes: effects on bacterial blood clearance capacity of the mononuclear phagocyte system. Clin Cancer Res. 1998;4(1):111-115.

11. Gan S, Yang P, Yang W. Photoactivation of alkyl C-H and silanization: a simple and general route to prepare high-density primary amines on inert polymer surfaces for protein immobilization. Biomacromolecules. 2009;10(5):1238-1243.

12. Liu T, Wang S, Chen G. Immobilization of trypsin on silica-coated fiberglass core in microchip for highly efficient proteolysis. Talanta. 2009;77(5):1767-1773. 
13. Jang LS, Liu HJ. Fabrication of protein chips based on 3-aminopropyltriethoxysilane as a monolayer. Biomed Microdevices. 2009;11(2):331-338.

14. Libertino S, Giannazzo F, Aiello V, et al. XPS and AFM characterization of the enzyme glucose oxidase immobilized on $\mathrm{SiO}(2)$ surfaces. Langmuir. 2008;24(5):1965-1972.

15. Nguyen TH, Kim YU, Kim KJ, Choi SS. Investigation of structural transition of dsDNA on various substrates studied by atomic force microscopy. J Nanosci Nanotechnol. 2009;9(3):2162-2168.

16. Yamazaki M, Ito T. Deformation and instability in membrane structure of phospholipid vesicles caused by osmophobic association: mechanical stress model for the mechanism of poly(ethylene glycol)-induced membrane fusion. Biochemistry. 1990;29(5):1309-1314.

17. Boni LT, Hah JS, Hui SW, Mukherjee P, Ho JT, Jung CY. Aggregation and fusion of unilamellar vesicles by poly(ethylene glycol). Biochim Biophys Acta. 1984;775(3):409-418.

18. Levy MS, O’Kennedy RD, Ayazi-Shamlou P, Dunnill P. Biochemical engineering approaches to the challenges of producing pure plasmid DNA. Trends Biotechnol. 2000;18(7):296-305.

19. Santra S, Wang K, Tapec R, Tan W. Development of novel dyedoped silica nanoparticles for biomarker application. J Biomed Opt. 2001;6(2):160-166.

20. Cui Z, Mumper RJ. Plasmid DNA-entrapped nanoparticles engineered from microemulsion precursors: in vitro and in vivo evaluation. Bioconjug Chem. 2002;13(6):1319-1327.

21. Conwell CC, Huang L. Recent advances in non-viral gene delivery. Adv Genet. 2005;53:3-18.

22. Torchilin VP. Multifunctional nanocarriers. Adv Drug Deliv Rev. 2006;58(14):1532-1555.

23. Barnes CA, Elsaesser A, Arkusz J, et al. Reproducible comet assay of amorphous silica nanoparticles detects no genotoxicity. Nano Lett. 2008;8(9):3069-3074.

24. Slowing II, Wu CW, Vivero-Escoto JL, Lin VS. Mesoporous silica nanoparticles for reducing hemolytic activity towards mammalian red blood cells. Small. 2009;5(1):57-62.

25. He X, Nie H, Wang K, Tan W, Wu X, Zhang P. In vivo study of biodistribution and urinary excretion of surface-modified silica nanoparticles. Anal Chem. 2008;80(24):9597-9603.

26. Burns AA, Vider J, Ow H, et al. Fluorescent silica nanoparticles with efficient urinary excretion for nanomedicine. Nano Lett. 2009;9(1):442-448.

27. Kabanov AV. Polymer genomics: an insight into pharmacology and toxicology of nanomedicines. Adv Drug Deliv Rev. 2006; 58(15):1597-1621.

28. Fischer D, Li Y, Ahlemeyer B, Krieglstein J, Kissel T. In vitro cytotoxicity testing of polycations: influence of polymer structure on cell viability and hemolysis. Biomaterials. 2003;24(7):1121-1131.
29. Jevprasesphant R, Penny J, Jalal R, Attwood D, McKeown NB, D'Emanuele A. The influence of surface modification on the cytotoxicity of PAMAM dendrimers. Int J Pharm. 2003;252(1-2):263-266.

30. Loyter A, Scangos G, Juricek D, Keene D, Ruddle FH. Mechanisms of DNA entry into mammalian cells. II. Phagocytosis of calcium phosphate DNA co-precipitate visualized by electron microscopy. Exp Cell Res. 1982;139(1):223-234.

31. Coonrod A, Li FQ, Horwitz M. On the mechanism of DNA transfection: efficient gene transfer without viruses. Gene Ther. 1997; 4(12):1313-1321.

32. Schmid SL, Fuchs R, Male P, Mellman I. Two distinct subpopulations of endosomes involved in membrane recycling and transport to lysosomes. Cell. 1988;52(1):73-83.

33. Roy I, Ohulchanskyy TY, Pudavar HE, et al. Ceramic-based nanoparticles entrapping water-insoluble photosensitizing anticancer drugs: a novel drug-carrier system for photodynamic therapy. $J \mathrm{Am}$ Chem Soc. 2003;125(26):7860-7865.

34. Wilhelm C, Billotey C, Roger J, Pons JN, Bacri JC, Gazeau F. Intracellular uptake of anionic superparamagnetic nanoparticles as a function of their surface coating. Biomaterials. 2003;24(6):1001-1011.

35. Davis SS. Biomedical applications of nanotechnology - implications for drug targeting and gene therapy. Trends Biotechnol. 1997; 15(6):217-224.

36. Roy I, Ohulchanskyy TY, Bharali DJ, et al. Optical tracking of organically modified silica nanoparticles as DNA carriers: A nonviral, nanomedicine approach for gene delivery. Proc Natl Acad Sci USA. 2005;102(2):279-284.

37. Zanta MA, Belguise-Valladier P, Behr JP. Gene delivery: a single nuclear localization signal peptide is sufficient to carry DNA to the cell nucleus. Proc Natl Acad Sci U S A. 1999;96(1):91-96.

38. Klichko Y, Liong M, Choi E, et al. Mesostructured silica for optical functionality, nanomachines, and drug delivery. J Am Ceram Soc. 2009;92(S1):S2-S10.

39. Coti KK, Belowich ME, Liong M, et al. Mechanised nanoparticles for drug delivery. Nanoscale. 2009;1(1):16-39.

40. Liong M, Lu J, Kovochich M, et al. Multifunctional inorganic nanoparticles for imaging, targeting, and drug delivery. ACS Nano. 2008;2(5):889-896.

41. Nguyen-Huu T, Lett C, Auger P, Poggiale JC. Spatial synchrony in host-parasitoid models using aggregation of variables. Math Biosci. 2006;203(2):204-221.

42. Lu J, Choi E, Tamanoi F, Zink JI. Light-activated nanoimpellercontrolled drug release in cancer cells. Small. 2008;4(4):421-426.
International Journal of Nanomedicine

\section{Publish your work in this journal}

The International Journal of Nanomedicine is an international, peerreviewed journal focusing on the application of nanotechnology in diagnostics, therapeutics, and drug delivery systems throughout the biomedical field. This journal is indexed on PubMed Central,

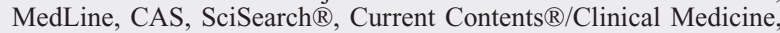

\section{Dovepress}

Journal Citation Reports/Science Edition, EMBase, Scopus and the Elsevier Bibliographic databases. The manuscript management system is completely online and includes a very quick and fair peer-review system, which is all easy to use. Visit http://www.dovepress.com/ testimonials.php to read real quotes from published authors. 